\title{
Inhibition of Stress-Induced Neuroendocrine and Behavioral Responses in the Rat by Prepro-Thyrotropin-Releasing Hormone 178-199
}

\author{
Robert F. McGivern,, ${ }^{1}$ Peter Rittenhouse, ${ }^{2}$ Fraser Aird, ${ }^{2}$ Louis D. Van de Kar, ${ }^{3}$ and Eva Redei ${ }^{2}$ \\ ${ }^{1}$ Department of Psychology, San Diego State University, San Diego, California 92182, 2Departments of Pharmacology \\ and Psychiatry, University of Pennsylvania, Philadelphia, Pennsylvania 19104, and ${ }^{2}$ Department of Pharmacology, Loyola \\ University, Maywood, Illinois 60153
}

\begin{abstract}
A corticotropin release-inhibiting factor (CRIF) in brain has been postulated for several decades, based on increased plasma levels of ACTH and corticosterone after hypothalamic-pituitary disconnection. Recent in vitro studies indicate that preproTRH178-199 may function as an endogenous CRIF, prompting us to examine stress-related neuroendocrine and behavioral responses after in vivo administration to the adult male rat. Animals that were administered prepro-TRH178-199 intravenously $5 \mathrm{~min}$ before restraint stress exhibited a significant attenuation of stress-induced elevations of $\mathrm{ACTH}$, corticosterone, and prolactin, as compared with controls infused with vehicle, whereas thyroid-stimulating hormone (TSH) secretion was not changed.

In behavioral studies of stress responsiveness, either the vehicle or prepro-TRH178-199 was administered intracerebroventricularly (ICV) $5 \mathrm{~min}$ before testing. In the open field,
\end{abstract}

prepro-TRH178-199 significantly increased grooming, locomotor activity, rearing, and sniffing behaviors. In the light/dark box, it significantly increased the time animals spent in the light compartment and increased the number of crossings between the light/dark compartments. In the plus maze, the peptide significantly increased the amount of time animals spent in the open arms. The same dose of peptide, administered ICV, had no effect on peripheral hormone release in response to restraint stress. Overall, these results support a role for prepro-TRH178199 in the inhibition of the neuroendocrine responses to stress at the level of the pituitary and indicate that it has central modulatory influences over stress-related behaviors.

Key words: ACTH; corticosterone; TSH; prolactin; stress; plus maze; light/dark box; arousal; grooming; activity; CRF; CRIF; $T R H$
Selye (1950) characterized the mammalian response to stress as an integration of neuroendocrine, autonomic, and behavioral reactions, mediated in large part by the pituitary adrenal system. The primary regulator of the adrenocortical response to stress is adrenocorticotropic hormone (corticotropin; ACTH), secreted from the anterior pituitary. Over the past four decades numerous studies have revealed a physiological role for ACTH and peptides derived from its precursor, pro-opiomelanocortin (POMC), on behavior, sensory processes, autonomic function, lyolysis, and immune function (Blalock, 1985; de Wied and Croiset, 1991). These diverse actions have led to the proposal that POMC may function as a homeostatic control system (de Wied and de Kloet, 1987).

Corticotropin-releasing factor $(\mathrm{CRF})$ is a primary regulator of POMC transcription and of the secretion of POMC peptides (Lundblad and Roberts, 1988; Autelitano et al., 1989). Since its identification in 1981 by Vale et al., CRF has been found to have a wide distribution in brain and to possess a variety of stressrelated behavioral effects beyond the release of ACTH (Feldman

\footnotetext{
Received Jan. 29, 1997; revised April 1, 1997; accepted April 8, 1997.

This work was supported by National Institute on Alcohol Abuse and Alcoholism Grant AA06478 and the Berman Foundation. Expert technical assistance was provided by Jennifer Choi, Keri Gibson, and Stephanie Robeck.

Correspondence should be addressed to Dr. Robert F. McGivern, 6363 Alvarado Road, Suite 200H, San Diego, CA 92120.

Dr. Aird's and Dr. Redei's present address: The Asher Center, Department of Psychiatry and Behavioral Sciences, Northwestern University Medical School, Ward 9-142, 303 East Chicago Avenue, Chicago, IL 60611.

Copyright (C) 1997 Society for Neuroscience $0270-6474 / 97 / 174886-09 \$ 05.00 / 0$
}

et al., 1995). Central actions of CRF include autonomic regulation and the elicitation of behavioral responses to stress that are situationally appropriate to facilitate "fight or flight" responses (Korte et al., 1993; Kalin et al., 1994). Thus CRF may be an integral part of the POMC homeostatic system or, alternatively, a neuromodulator of the stress response independent of POMC.

An inhibitory influence on pituitary ACTH release is thought to be a third important component of this stress regulatory system. The existence of a corticotropin release-inhibiting factor (CRIF) has been postulated on the basis of elevated levels of ACTH after disconnection of the pituitary from the hypothalamus (Harris, 1948; Egdahl, 1960; Halasz et al., 1967; Engler et al., 1988; Mercer et al., 1989). Recently, we demonstrated that prepro-TRH178199, an intervening peptide of TRH prohormone, has corticotropin release-inhibiting properties (Redei et al., 1995a,b). This peptide inhibits both basal and stimulated ACTH secretion by $40-50 \%$ at physiologically relevant concentrations in a mouse pituitary tumor cell line and also in rat primary cultures of anterior pituitary, suggesting that prepro-TRH178-199 may function as an endogenous CRIF.

Other biochemical and anatomical evidence supporting a physiological significance for this peptide in the regulation of ACTH secretion includes data indicating that it is processed from thyroid-releasing hormone prohormone (prepro-TRH) in vivo, is found in the paraventricular nucleus of the hypothalamus and external zone of the median eminence, and is secreted from hypothalamic slices in vitro (Lechan et al., 1987; Liao et al., 1988; Valentijn et al., 1991). Immunocytochemically, prepro-TRH178- 
199 also has been localized in several brain areas that are not linked directly to control of pituitary hormone secretion. These include the periaqueductal gray (PAG), periventricular nucleus of the thalamus, and lateral septum (Liao et al., 1988). This distribution suggests that central actions of prepro-TRH178-199 might modulate behavioral reactions to stress. In the present studies we have examined the in vivo actions of this peptide on hormonal responses to stress and stress-related behaviors.

\section{MATERIALS AND METHODS}

Viral-free adult male Sprague Dawley rats from Charles River (Hollister, CA) were used in all experiments. Animals were 4-6 months of age at the time of testing for restraint stress and 2 months of age for shock stress. Group housing was maintained throughout except under certain experimental conditions, as noted below. The vivarium was maintained at $21^{\circ} \mathrm{C}$ $\left( \pm 2^{\circ} \mathrm{C}\right)$ with an average relative humidity of $40-50 \%$. Lighting was on a 12:12 light/dark schedule, with lights on at $0600 \mathrm{hr}$ and food and tap water available ad libitum. All procedures were approved by the San Diego State University or University of Pennsylvania Animals Use Committee.

Cannulation. For central administration of prepro-TRH178-199, animals were implanted with a 22 gauge stainless steel guide cannula aimed at the lateral ventricle. Implantation was done under ketamine-xylazine $(100 \mathrm{mg} / \mathrm{kg}$ ketamine- $15 \mathrm{mg} / \mathrm{kg}$ xylazine, i.m.) anesthesia, using stereotaxic coordinates taken from the atlas of Paxinos and Watson (1986), and was performed at least $4 \mathrm{~d}$ before behavioral testing. The coordinates used were $1.0 \mathrm{~mm}$ posterior to Bregma, $2.0 \mathrm{~mm}$ lateral to the midline, and $4.1 \mathrm{~mm}$ below the top of the skull. At the end of behavioral testing, placements were verified by anesthetizing the animal with pentobarbital $(65 \mathrm{mg} / \mathrm{kg})$ and injecting $10 \mu \mathrm{l}$ trypan blue staining solution into the ventricle just before decapitation. Only data from animals in which the stain was present in the ventricle were included for analysis.

To obtain serial blood samples, we implanted animals with an atrial cannula under ketamine-xylazine anesthesia $72-96 \mathrm{hr}$ before testing. SILASTIC tubing ( 0.037 inch outer diameter, 0.020 inch inner diameter) was inserted into the right atrium via the right jugular vein. The cannula was externalized at the back of the neck. Patency was maintained by flushing the cannula daily with sterile saline containing heparin (20 $\mathrm{U} / \mathrm{ml}$ ). Animals were housed in the bleeding chambers $3 \mathrm{~d}$ before surgery and for the postsurgery period to avoid the stress of a novel environment Food and water were available ad libitum, and the lighting schedule remained as described above. At the time of serial blood sampling, the SILASTIC cannula was attached to an extension tubing that exited the top of the enclosed chamber, allowing the animal to move freely about the chamber.

Restraint stress. The ability of prepro-TRH178-199 to inhibit stressinduced hormone secretion was examined in rats exposed to restraint stress for $5 \mathrm{~min}$. Animals were injected intravenously or intracerebroventricularly (ICV) with prepro-TRH178-199 or the vehicle 5 min before the restraint period. For central administration of prepro-TRH178-199, the animals were infused ICV with the peptide $(0.6$ or $6 \mu \mathrm{g} / \mathrm{kg})$ or the vehicle $(0.9 \%$ saline, $0.01 \%$ ascorbic acid) in a $3 \mu \mathrm{l}$ vol over a $45 \mathrm{sec}$ period $5 \mathrm{~min}$ before restraint. For peripheral administration preproTRH178-199 (100 or $200 \mu \mathrm{g} / \mathrm{kg})$ was infused in the home cage through the indwelling atrial cannula 5 min before restraint.

The animals were restrained in opaque plastic tubes $(3.5$ inch inner diameter $\times 7$ inch length) between 1100 and $1300 \mathrm{hr}$. Animals rested on a platform that ran the length of the tube. To allow air circulation, we drilled the endcaps with 0.75 inch center holes and the top of the tube with two 0.50 inch holes. After restraint, the animals were connected immediately with an extender tubing for serial bleeding and subsequently were returned to the home cage. Baseline plasma blood samples were obtained $90 \mathrm{~min}$ before restraint.

Blood samples $(300 \mu \mathrm{l})$ were obtained at 10, 20, 30, 60, and $120 \mathrm{~min}$ after the onset of stress. Blood volume was replaced with sterile saline containing heparin $(10 \mathrm{U} / \mathrm{ml})$ and gentamicin $(0.03 \mathrm{mg} / \mathrm{ml})$ immediately after each sample was obtained. Samples were collected in tubes on ice containing EDTA $(1.5 \mathrm{mg} / \mathrm{ml})$ and aprotinin $(250 \mathrm{KIU} / \mathrm{ml})$ and subsequently centrifuged at $2500 \mathrm{rpm}$. The plasma was stored at $-70^{\circ} \mathrm{C}$ for determination of ACTH, TSH, corticosterone (CORT), and prolactin (PRL) concentration by radioimmunoassays.

Shock stress. Exposure to a brief footshock was used to examine the effects of prepro-TRH178-199 on ACTH secretion under milder stress conditions. Animals were subjected to an intermittent footshock stress
( $0.2 \mathrm{~mA} ; 0.5 \mathrm{sec}$ on, $0.5 \mathrm{sec}$ off $)$ for $15 \mathrm{sec}$ between 1000 and $1300 \mathrm{hr}$. Prepro-TRH178-199 (10 or $100 \mu \mathrm{g} / \mathrm{kg})$ or the vehicle was infused intravenously $5 \mathrm{~min}$ before the stress through the extender connected to the indwelling atrial cannula. Blood samples $(0.3 \mathrm{ml})$ were obtained in the home cage immediately before placing the animal in the cage, and at 20 and 40 min poststress. Because of the smaller size of the animals, fewer time samples were taken, and the sampling period was designed to detect peak CORT levels in plasma.

Radioimmunoassays (RIAs). ACTH was measured as described previously (Fitch et al., 1992) in unextracted plasma $(25 \mu l)$ with antiserum (INCSTAR, Stillwater, MN) that recognizes ACTH 1-24 and ACTH 1-39 on an equimolar basis with ${ }^{125} \mathrm{I}-\mathrm{ACTH}$ as the tracer (ICN Biomedicals, Carson, CA). The assay sensitivity was $0.5 \mathrm{pg} /$ tube with an intraassay coefficient of variation of $6.3 \%$. CORT was measured in unextracted plasma as described previously (Fitch et al., 1992), using antibody raised against corticosterone-3-carboxymethyloxime:BSA, with ${ }^{125} \mathrm{I}$ corticosterone-3-carboxymethyloxime as a tracer (ICN). The assay sensitivity was $0.3 \mathrm{ng} /$ tube, and the intra-assay coefficient of variation was 7.5\%. TSH standards and specific antiserum were obtained from the National Hormone and Pituitary Agency [National Institute of Diabetes and Digestive and Kidney Diseases (NIDDK), Bethesda, MD]. Rat TSH RP-2 was used for the iodination and standards. The assay sensitivity was $1.0 \mathrm{pg} /$ tube with an intra-assay coefficient of variation of $10.5 \%$. Prolactin was measured as described previously (Li et al., 1993), using reagents obtained from the National Hormone and Pituitary Agency (NIDDK). Rat PRL-I-6 was used for iodination and rPRL-RP-3 for standards. The assay sensitivity was $0.02 \mathrm{ng} /$ tube with an intra-assay coefficient of variation of $4.8 \%$.

Open field behavior. An open field test was conducted between 0930 and $1300 \mathrm{hr}$ to examine the effects of the peptide on behavior in a novel environment after ICV injection in the home cage of the peptide or vehicle $5 \mathrm{~min}$ before testing. Animals were placed in the center of a novel 15-inch-diameter open field, and behavior was videotaped for $30 \mathrm{~min}$. The circular open field was enclosed with an 18-inch-high clear Plexiglas wall. The floor was divided into four quadrants for assessment of movement within the field. Illumination was $\sim 160$ lux. Open field behaviors were scored by a trained observer who was blind to the treatment conditions. The measures scored included (1) activity, (2) rearing, (3) grooming, (4) active sniffing, (5) gnawing, and (6) number of fecal boli. Rearing, activity, and grooming were quantified for the entire period. Sniffing and gnawing were scored as present (score $=1$ ) or absent (score $=0$ ) in each of the six 5 min periods during the test. Active sniffing was defined as olfactory investigation of the floor or wall, or the animal's raising its head and moving its vibrissae. Rearing was defined as both forelegs raised from the floor, and each incidence was scored. Activity was scored for each quadrant entered. An entry was defined as movement of both forelegs into an adjacent quadrant. Grooming was scored in seconds.

Elevated plus maze. Basal Plus Maze Performance assesses anxietyrelated behavior in the rat (Handley and McBlane, 1993; Landgraf et al., 1995). The test exploits a rodent's natural conflict between avoidance and exploration of open, elevated areas. The maze consisted of four Plexiglas arms extending from a 12 -inch-square center suspended 30 inches above the floor. The arms were positioned $90^{\circ}$ from each other to form the shape of a plus sign. Each arm was 24 inches long and 5.5 inches wide. Two of the opposing arms were made of black Plexiglas with 5-inch-high walls surrounding the three sides of the arm. The other two opposing arms and the center platform were made of clear Plexiglas.

The animals were injected ICV 5 min before testing, as described above. Testing was conducted between 0900 and $1230 \mathrm{hr}$. At the beginning of the test the animal was placed onto the center platform facing a closed arm. The 20 min test session was videotaped and subsequently was scored by a trained observer who was blind to the treatment conditions. The following measures were taken: (1) the latency to enter the first arm; (2) the number of open and closed arm entries; (3) the total time spent in the open arms, closed arms, and the center; (4) the total time spent grooming. An entry into an arm was defined as placing at least both forepaws onto a given arm. Average lighting in the testing room at the level of the maze was 160 lux. Feces were removed, and the maze was cleaned with an alcohol/acetic acid solution between successive tests to remove odor cues.

Light/dark box. The light/dark box also was used to assess the antianxiety properties of prepro-TRH178-199. The box was divided into an 18 inch long $\times 15$ inch wide $\times 15$ inch high compartment open at the top with three walls, and the floor was made of clear Plexiglas. The fourth 
wall served as the divider between the two compartments and contained a 3 inch wide $\times 4$ inch high opening at floor level. This allowed the animal entry into a 12 inch long $\times 15$ foot wide dark compartment that was fully enclosed. The four walls, the ceiling, and the floor of the dark compartment were made of black Plexiglas. A door at the back of the box served to allow access for cleaning and removal of the animals after testing. The test apparatus was placed on a 30-inch-deep benchtop. At the beginning of testing, each animal was placed in the center of the light compartment. Behavior subsequently was videotaped for $15 \mathrm{~min}$. Behaviors were scored by an observer who was blind to the treatment conditions. The measures scored were (1) initial latency to enter the dark compartment, (2) number of compartment entries, and (3) total time spent in each compartment. Average lighting in the testing room at the level of the maze was 200 lux. Feces were removed, and the maze was cleaned with an alcohol/acetic acid solution between successive tests to remove odor cues. Injections were administered ICV, as described above. Testing was done between 0930 and $1300 \mathrm{hr}$.

Data analysis. Parametrically distributed data were analyzed by oneway ANOVA with repeated measures over the time factor. For nonparametrically distributed data, a Kruskal-Wallis one-way ANOVA was used on the total score for the entire period. Post hoc comparisons used Student's $t$ test or the sign test. For the open field measures, data were analyzed over six 5 min periods during the $30 \mathrm{~min}$ of observation.

Peptide analysis. Prepro-TRH178-199 used in these studies was synthesized at the Protein Chemistry Laboratory of the Medical School of the University of Pennsylvania. Subsequently, the peptide was analyzed by mass spectrometry. The chemical integrity of this peptide is very important, particularly in light of a recent report by Nicholson and Orth (1996), which failed to observe any inhibitory activity of preproTRH178-199 on ACTH secretion by anterior pituitary cells. The authors used a ppTRH178-199 peptide synthesized in 1986 (Lot 010658, Peninsula Laboratories, Belmont, CA), and we also observed no activity of this lot of peptide in vitro (Redei et al., 1995b). Electronspray ionization-mass spectrometry (ESI-MS) and time of flight (TOF)-MS confirmed that the peptide used by these investigators (and us) contained significant amounts of oxidated and other unidentified products. Oxidation of the methionine amino acid 20 in prepro-TRH178-199 would result in the observed mass increase of 16 units determined by mass spectrometry and could be responsible for the loss of bioactivity observed by ourselves and others (Nicholson and Orth, 1996; Redei et al., 1995b).

\section{RESULTS}

\section{Peptide analysis}

Electronspray ionization-mass spectrometry and TOF-MS analyses of the peptide used in the present study revealed little oxidation and showed an intact peptide.

Effect of peripheral administration of prepro-TRH178199 on neuroendocrine responses to restraint stress

Peripheral administration of prepro-TRH178-199 5 min before the onset of restraint stress significantly inhibited ACTH secretion, as compared with the vehicle treatment and as indicated by Drug $\times$ Time interaction $\left(F_{(10,70)}=2.74 ; p<0.01\right)$. A significant inhibition was observed with both 100 and $200 \mu \mathrm{g} / \mathrm{kg}$ of preproTRH178-199 from 10 to $30 \mathrm{~min}$ after the onset of stress. No significant difference was detected between the two doses of the peptide to inhibit stress-induced ACTH secretion. ACTH levels returned to baseline by $60 \mathrm{~min}$ in all groups. Data are shown in Figure 1.

The decrease in stress-induced ACTH secretion was accompanied by a significant reduction in the duration of CORT secretion in animals administered either dose of prepro-TRH178-199 $\left(\right.$ Drug $\times$ Time $\left.; F_{(10,70)}=2.43 ; p<0.02\right)$. Although the initial CORT response in peptide-treated animals was similar to that in controls, the decreased ACTH stimulation resulted in a significant decrease in plasma CORT levels by $60 \mathrm{~min}(p<0.01)$. CORT levels returned to baseline by $120 \mathrm{~min}$ after the onset of stress in all groups. Data are shown in Figure 1.

Stress-induced prolactin secretion also was inhibited by periph- eral administration of prepro-TRH178-199 (Fig. 1; Drug $\times$ Time; $\left.F_{(10,70)}=3.83 ; p<0.001\right)$. Restraint induced a three- to fourfold rise in plasma prolactin levels in vehicle-treated animals by $10 \mathrm{~min}$ after the onset of the 5 min stress $(p<0.001)$, but only a twofold rise in animals administered $100 \mu \mathrm{g} / \mathrm{kg}$ of the peptide, a difference that was significant only marginally, as compared with baseline $(p<0.06)$. No evidence of a stress-induced rise in plasma prolactin at $10 \mathrm{~min}$ was observed in animals administered 200 $\mu \mathrm{g} / \mathrm{kg}$ of prepro-TRH178-199. The plasma TSH level was not influenced significantly by either dose of prepro-TRH178-199 (Fig. 1).

\section{Effect of peripheral administration of prepro-TRH178- 199 on neuroendocrine responses to shock stress}

The analysis of ACTH revealed a main effect of time $\left(F_{(2,24)}=\right.$ 18.64; $p<0.0001)$ as well as a Dose $\times$ Time interaction $\left(F_{(4,24)}=\right.$ 3.31; $p<0.05$; Fig. 2). As shown in Figure 2, plasma CORT levels were attenuated significantly at 20 and $40 \mathrm{~min}$ by both doses of prepro-TRH178-199, as compared with the vehicle $(p<0.05)$. The analysis revealed a significant main effect for dose $\left(F_{(2,12)}=\right.$ 5.34; $p<0.05)$ and time $\left(F_{(2,24)}=29.10 ; p<0.0001\right)$, as well as a Dose $\times$ Time interaction $\left(F_{(4,24)}=5.69 ; p<0.01\right)$.

\section{Effect of prepro-TRH178-199 on open field behavior}

Intracerebroventricular (ICV) administration of preproTRH178-199 induced significant increases in several open field behaviors, as shown in Figure 3. With respect to locomotor activity, prepro-TRH178-199 induced an increase that was dosedependent. The repeated measures ANOVA revealed a significant main effect of dose $\left(F_{(2,26)}=6.19 ; p<0.01\right)$ and a marginal Time $\times$ Dose interaction $\left(F_{(10,130)}=1.81 ; p=0.06\right)$. The 6.0 $\mu \mathrm{g} / \mathrm{kg}$ dose of prepro-TRH178-199 (high dose) produced a significant increase in overall activity $(p<0.0001)$ during the $30 \mathrm{~min}$ test session, as compared with the $0.6 \mu \mathrm{g} / \mathrm{kg}$ dose of preproTRH178-199 (low dose) or the vehicle. The low dose significantly inhibited activity during the first 5 min of testing $(p<0.05)$.

Rearing behavior was increased significantly throughout the test session by the high dose of prepro-TRH178-199 but not the low dose $\left(F_{(2,26)}=4.05 ; p<0.03\right)$. A significant Time $\times$ Dose interaction $\left(F_{(10,130)}=1.94 ; p<0.05\right)$ revealed that the low dose of the peptide significantly inhibited rearing, as compared with the high dose and vehicle treatment during the first 5 min of testing $(p<0.03)$.

Grooming behavior in the open field was increased significantly throughout the test session by the high dose of prepro-TRH178199 , but not by the low dose, as compared with vehicle treatment $\left(F_{(2,26)}=9.13 ; p<0.001\right)$. The effect of the low dose did not differ from the vehicle treatment at any time point.

Active sniffing during the test session was increased significantly by the high dose of prepro-TRH178-199 ( $p<0.02$ ). No other significant effects of prepro-TRH178-199 on open field behavior were observed.

\section{Behavioral effects of prepro-TRH178-199 in the elevated plus maze and the light/dark box}

Animals administered $6 \mu \mathrm{g} / \mathrm{kg}$ of prepro-TRH178-199 spent significantly more time in the open arms of the elevated plus maze, as shown in Figure 4. Analysis of the total time spent in the open arms revealed a significant main effect of treatment $\left(F_{(2,20)}\right.$ $=4.66 ; p<0.03)$. Post hoc analyses revealed that the high dose of the peptide induced a significant increase in the time spent in the open arms, as compared with the low dose $(p<0.001)$, but not the vehicle treatment. The low dose induced a significant decrease 

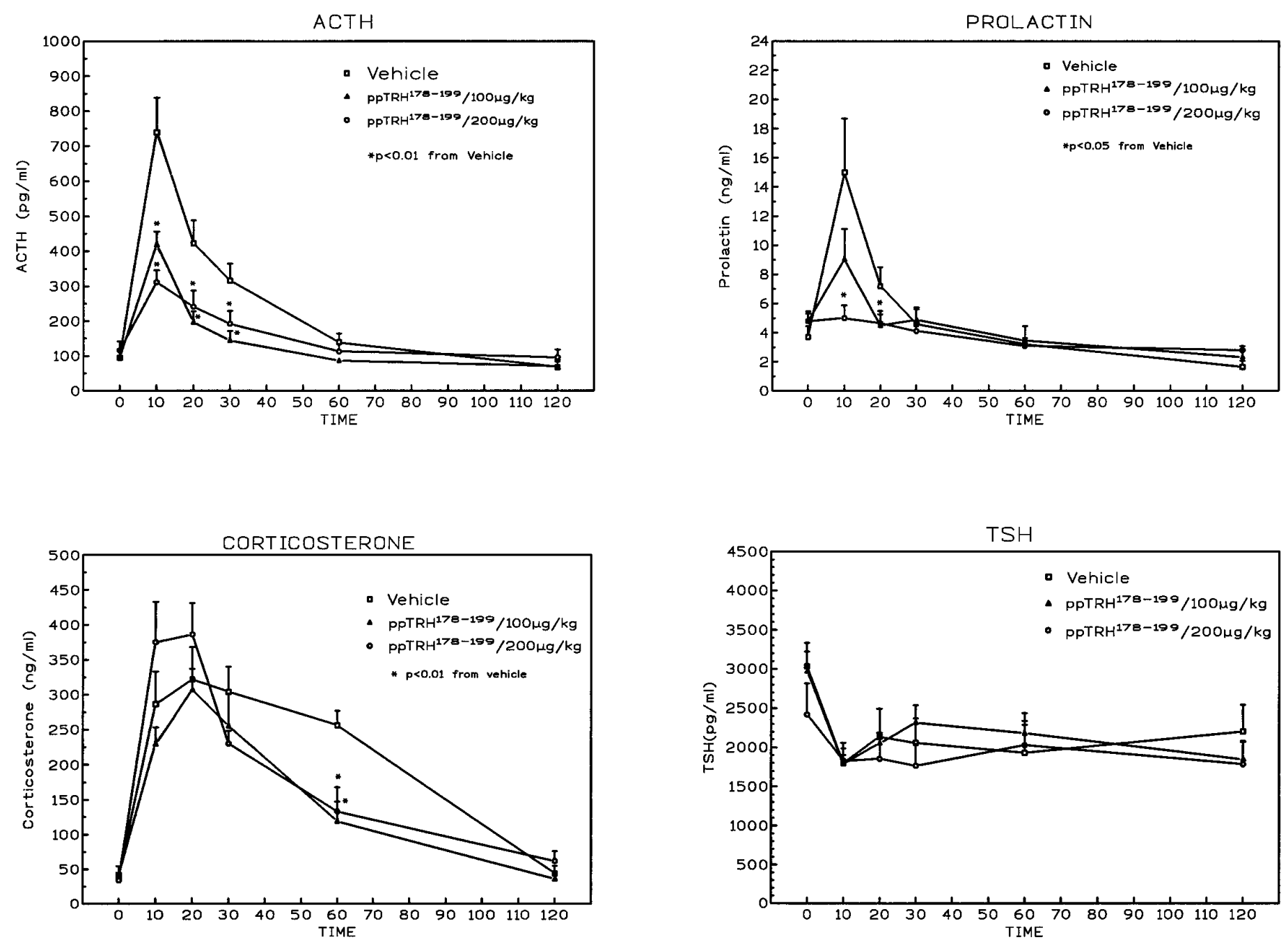

Figure 1. ACTH, corticosterone, prolactin, and TSH secretion in response to 5 min restraint stress. Data are mean and SEM of five to six animals per treatment. The animals were restrained between 1100 and $1300 \mathrm{hr}$. Prepro-TRH178-199 (100 or $200 \mu \mathrm{g} / \mathrm{kg})$ was infused in the home cage through the indwelling atrial cannula 5 min before restraint. After restraint the cannula was connected immediately with an extender tubing for serial bleeding, and the animals subsequently were returned to the home cage. ${ }^{*} p<0.05$ from both doses of prepro-TRH178-199.

in time spent in the open arms, as compared with the vehicle treatment $(p<0.05)$.

The number of arms visited was increased significantly by the high dose of prepro-TRH178-199 $\left(F_{(2,20)}=4.26 ; p<0.03\right)$, as compared with both other groups $(p<0.05)$, whereas no significant effect was observed in the ratio of light/dark arm entries among the groups $\left(F_{(2,20)}=2.40 ; p<0.12\right)$. Total time spent grooming did not differ significantly between the groups (Veh, $144 \pm 31 \mathrm{sec} ; 0.6 \mu \mathrm{g} / \mathrm{kg}$ prepro-TRH178-199, $122 \pm 39 \mathrm{sec} ; 6.0$ $\mu \mathrm{g} / \mathrm{kg}$ prepro-TRH178-199, $72 \pm 16 \mathrm{sec}$ ), nor was a significant difference observed in the initial latency to enter the first arm (Veh, $26.1 \pm 8.2 \mathrm{sec} ; 0.6 \mu \mathrm{g} / \mathrm{kg}$ prepro-TRH178-199, $26.2 \pm 14.5$ sec; $6.0 \mu \mathrm{g} / \mathrm{kg}$ prepro-TRH178-199, $18.0 \pm 7.0 \mathrm{sec}$ ).

Similar effects of the high dose of the peptide were observed in the light/dark box, as shown in Figure 5. The total time spent in the light chamber was increased significantly by the high dose, but not by the low dose, in comparison with vehicle treatment $(p<$ $0.05)$. The number of crossings between the light and dark chambers also was increased significantly by the high dose of preproTRH178-199, but not by the low dose, in comparison with vehicle treatment $(p<0.05)$. No significant difference was observed among the treatments in the initial latency to enter the dark chamber (Veh, $17.8 \pm 4.3 \mathrm{sec} ; 0.6 \mu \mathrm{g} / \mathrm{kg}$ prepro-TRH178-199, $18.8 \pm 3.5 \mathrm{sec} ; 6.0 \mu \mathrm{g} / \mathrm{kg}$ prepro-TRH178-199, $17.2 \pm 9.7 \mathrm{sec})$.

\section{Effects of ICV prepro-TRH178-199 on neuroendocrine responses to restraint stress}

To test whether the behavioral effects of the centrally administered peptide could be attributable to its ACTH release-inhibiting activity, we conducted restraint stress studies after ICV administration of 0.6 and $6 \mu \mathrm{k} / \mathrm{kg}$ of prepro-TRH178-199. Restraint stress produced ACTH, CORT, TSH, and PRL responses that paralleled those observed in the animals administered the peptide intravenously, but the ICV administration of doses of preproTRH178-199, which were behaviorally active, produced no significant effects on secretory patterns of ACTH, CORT, TSH, or $\mathrm{PRL}$ in response to restraint stress (data not shown).

\section{DISCUSSION}

Peripheral infusion of prepro-TRH178-199 before stress significantly diminished pituitary-adrenal activation and prolactin release, whereas central infusion into the lateral ventricle produced 

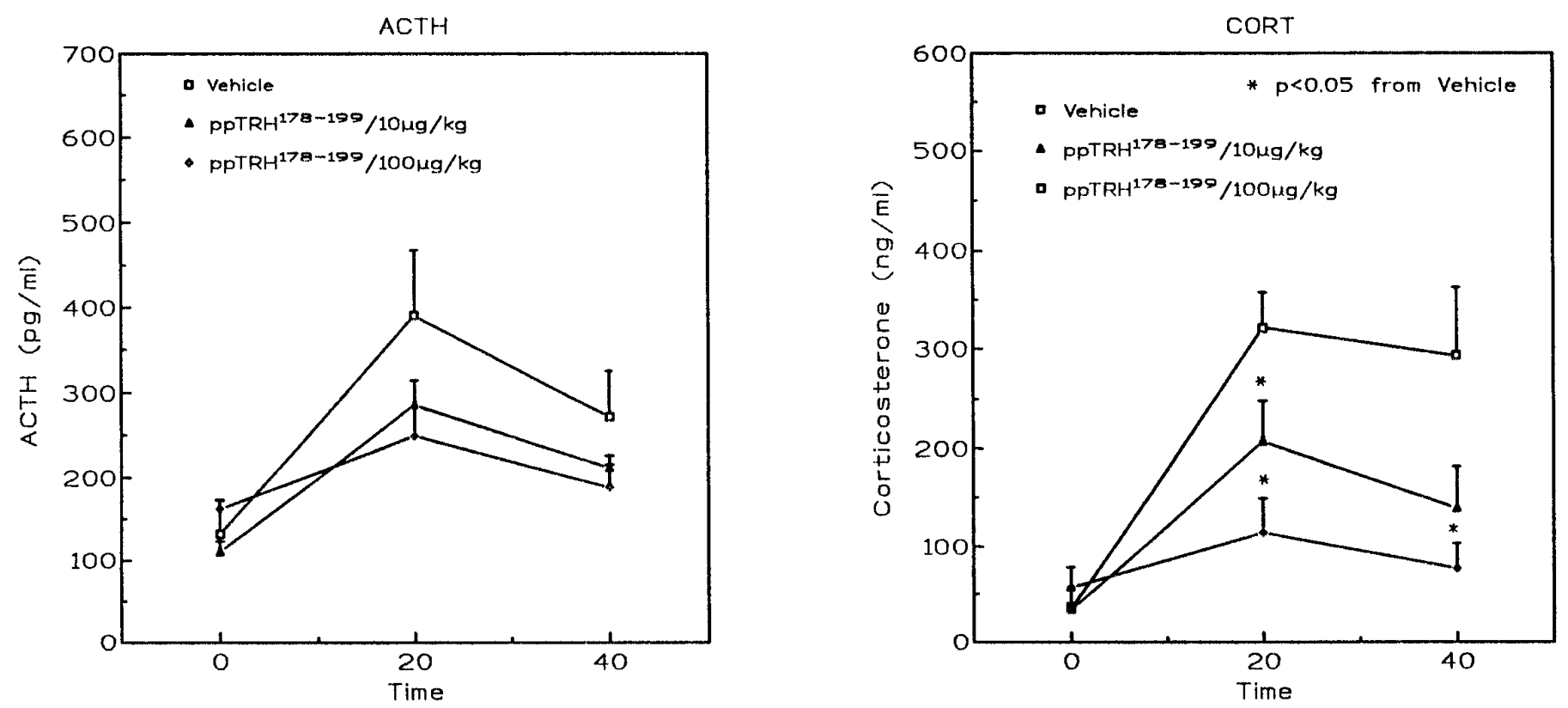

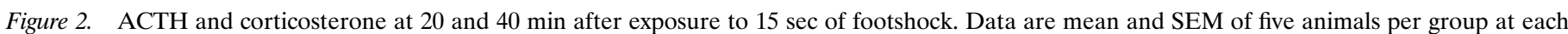

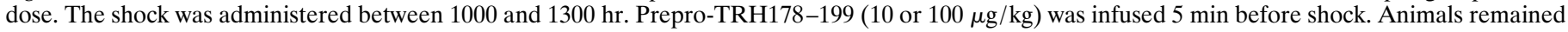
in the cage for the duration of the experiment.

behavioral results, suggesting both arousing and anxiolytic effects in the presence of a novel environment. These studies are the first to show that an endogenous peptide can reduce both neuroendocrine and behavioral manifestations of stress.

The inhibition of ACTH secretion by prepro-TRH178-199 in animals exposed to restraint stress is concordant with our previous in vitro findings (Redei et al., 1995a,b) and contradict those of Nicholson and Orth (1996). The reason for this discrepancy seems to be related primarily to the peptide preparation, because we also found no ACTH inhibitory activity of the same peptide preparation (Redei et al., 1995b). The inhibitory actions of preproTRH178-199 on HPA activity also are consistent with its immunocytochemical identification in the pars parvocellularis of the hypothalamus and in the external zone of the median eminence, suggesting that it may be released from the median eminence in response to an appropriate stimulus (Bulant et al., 1988; Liao et al., 1988). The inhibition of ACTH and PRL after peripheral administration of the peptide indicates that its effects are at the level of the pituitary.

The overall secretion of CORT was diminished significantly by $60 \mathrm{~min}$ in stressed animals pretreated with prepro-TRH178-199, although peak levels at 20-30 min after the onset of stress did not differ significantly from controls. In contrast, the CORT rise was reduced significantly in response to a much milder stress, the footshock stress in the presence of a much lower preproTRH178-199 peptide concentration. This difference in the early response of CORT in peptide-treated animals exposed to restraint versus shock stress may be attributable to the fact that the adrenal reached its maximal responsiveness to ACTH $(\sim 400 \mathrm{pg} / \mathrm{ml}$ of ACTH), which is close to the plasma ACTH concentration that we observed after prepro-TRH178-199 treatment in the restraint stress paradigm. In contrast, plasma ACTH response to the footshock stress is lower after prepro-TRH178-199 administration; therefore, adrenal cortex stimulation is submaximal.

Alternatively, immunoreactive ACTH-like peptides with differing biological activity may be secreted from the anterior pituitary under different conditions (Engeland et al., 1989), or CORT responsiveness to ACTH can be modified by a series of synergizing factors at the adrenal level, including CRF (van Oers, 1992). Furthermore, even when total CORT response to stress is unchanged, free CORT could follow changes in plasma ACTH, as shown for rats selectively bred for different dopamine responsiveness (Rots, 1996).

The inhibition of stress-induced prolactin release by peripheral administration of prepro-TRH178-199 was the most surprising finding in the present study. The mechanism whereby this occurs presently is unknown. This inhibition probably is not attributable to an increase in dopaminergic tone (Reichlin, 1992) because prepro-TRH178-199 administration did not influence basal prolactin secretion. Physiologically, ACTH and PRL secretion are both increased by many stressors. It will be interesting to see whether prepro-TRH178-199 is responsible for the decreased ACTH response to stress (Walker et al., 1995) or for the lack of PRL responses to stress during lactation (Higuchi et al., 1989).

A potential mechanism mediating the inhibition of stressinduced secretion of ACTH and PRL may involve vasopressin (AVP). Although stress-induced secretion of ACTH is thought to be dependent on CRF, under stress-specific conditions the stimulatory influence of AVP is highly significant (de Goeij et al., 1993; Romero et al., 1993). This influence can be blocked by a $V_{1}$ receptor antagonist (Kjaer et al., 1994). Stress-induced PRL secretion is thought to be modulated by TRH, AVP, and oxytocin in addition to other known or unknown regulators (Liu and BenJonathan, 1994). Moreover, prepro-TRH178-199 immunoreactive fibers have been observed in the posterior pituitary, and stress-induced PRL release also can be blocked by a $\mathrm{V}_{1}$ receptor antagonist (Liao et al., 1988; Kjaer et al., 1994). Although the effects of prepro-TRH178-199 on the actions of prolactin stimulatory peptides or putative prolactin inhibitory factors (BenJonathan, 1990) remain to be determined, prepro-TRH178-199 may act via the signal transduction mechanisms of the $V_{1}$ receptor. It should be noted that this peptide may have a more ubiq- 

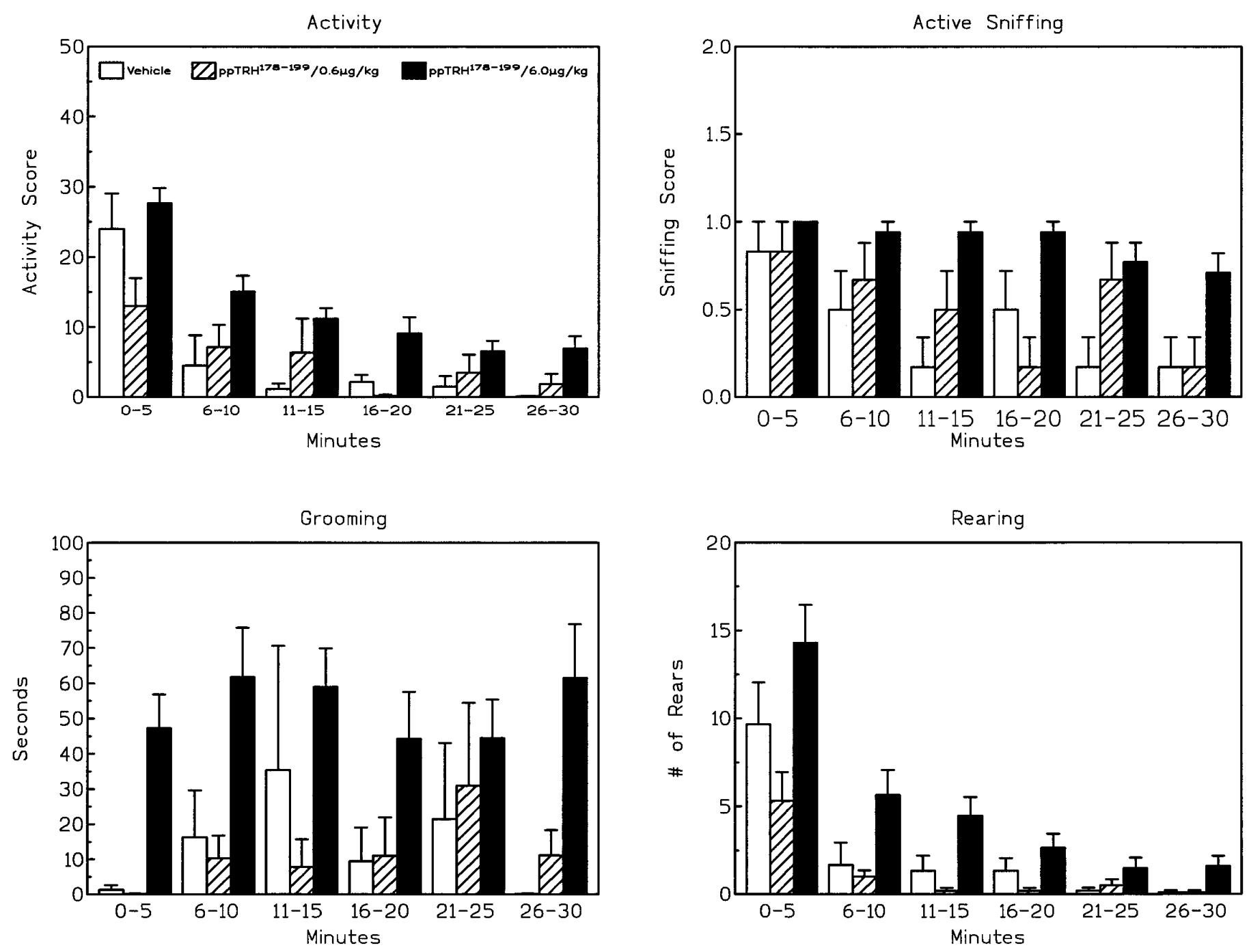

Figure 3. Open field behaviors after ICV infusion of prepro-TRH178-199 or the vehicle in a $3 \mu \mathrm{l}$ vol over a 45 sec period 5 min before testing. Animals were placed in the center of a 15 -inch-diameter open field, and behavior was videotaped for $30 \mathrm{~min}$. Data are mean and SEM of six vehicle, six low dose prepro-TRH178-199 (0.6 $\mu \mathrm{g} / \mathrm{kg})$-treated, and 17 high dose prepro-TRH178-199 $(6.0 \mu \mathrm{g} / \mathrm{kg})$-treated animals.

uitous inhibitory effect on anterior pituitary hormone secretion in light of recent studies demonstrating a prepro-TRH178-199 inhibition of growth hormone secretion in the rat and chicken (Roussel et al., 1994; Harvey and Cogburn, 1996).

The behavioral responses that we observed after ICV administration are consistent with the hypothesized "stress reduction" properties of prepro-TRH178-199. In the light/dark box and the plus maze test, the rat was placed in an approach-avoidance situation in which fear of an open space competes with the attraction of exploring a novel area. To a lesser degree these same factors are also integral to the open field test. Central administration of prepro-TRH178-199 increased the amount of time an animal spent in the lighted compartment of the light/dark box, suggesting that it reduced the fear of open spaces. The animals not only spent more time in the lighted area but spent more time actively investigating their environment, as indicated by the more than threefold increase in compartmental crossings, as compared with vehicle-treated animals. A similar pattern of increased locomotor activity was observed in the open field test.

The results from the plus maze experiment did not parallel directly those of the light/dark box. Some evidence for an anxio- lytic effect of the high dose of prepro-TRH178-199 in the plus maze was provided by the significant increase in the number of arms visited by these animals, as compared with controls or with the low dose-treated animals. However, treatment with the high dose of prepro-TRH178-199 did not increase the time spent in the open arms, as compared with the vehicle. One potential reason may be that the plus maze is inherently more stressful than the light/dark box.

The low dose of the peptide significantly decreased the time spent in the open arms, as compared with animals treated with the vehicle or the high dose. This inhibitory effect of the low dose of prepro-TRH178-199 was similar to the inhibitory effect of this dose on locomotor behavior and rearing in the open field during the first $5 \mathrm{~min}$. Together, these results suggest the possibility of dose-related effects of the peptide, which may have an inverted U-shaped function, a function that has been observed consistently for the behavioral and biochemical effects of ACTH and related peptides (Gold and van Buskirk, 1976; Lichtensteiger and Monnet, 1979; Sands and Wright, 1979; Schotman and Allaart, 1981). An alternative possibility is that these dose-related effects reflect 
Time in Light Compartment

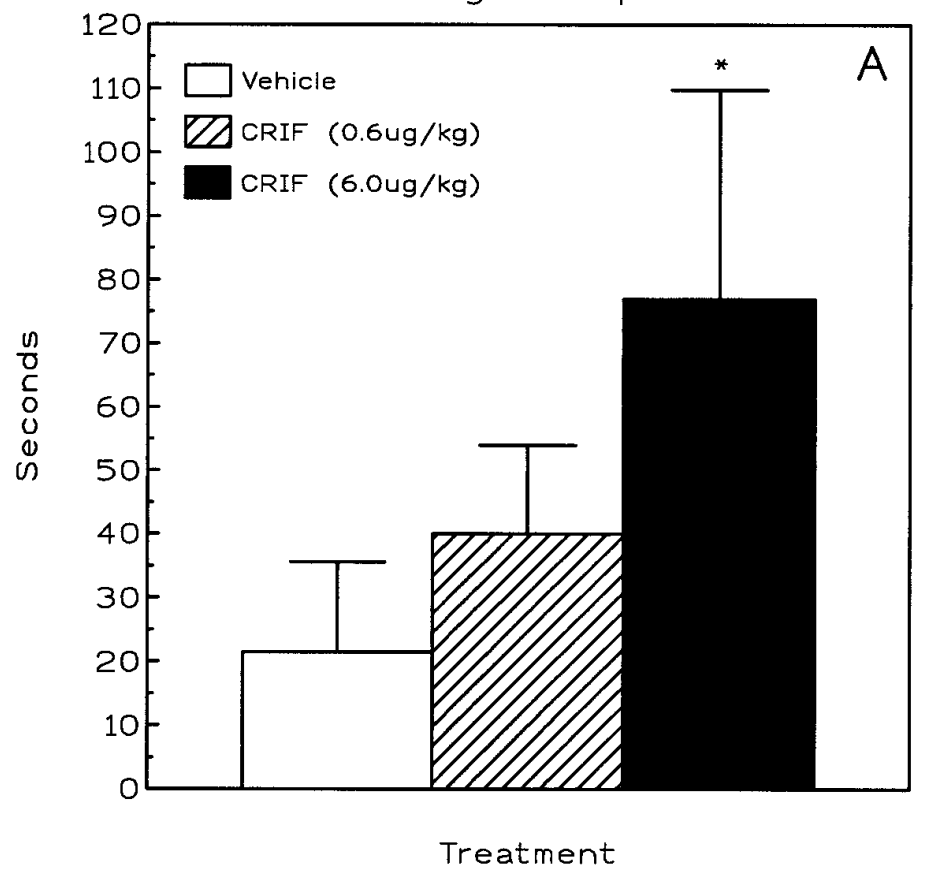

Compartmental Crossings

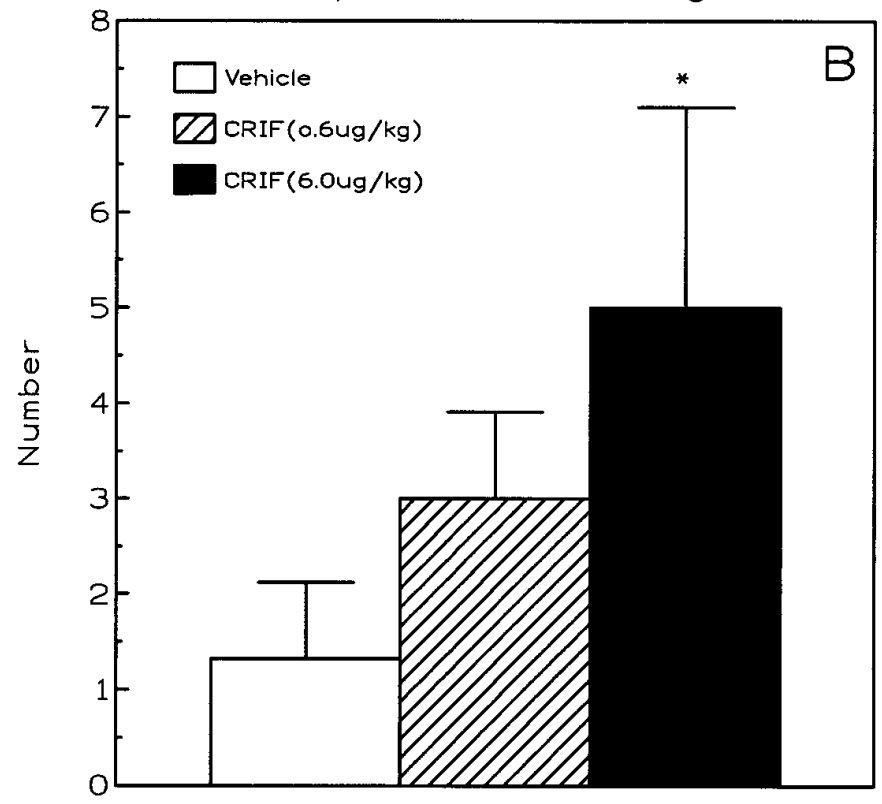

Treatment

Figure 4. Behavioral responses in the light/dark box after ICV infusion of prepro-TRH178-199 or the vehicle. At the beginning of testing, each animal was placed in the center of the light compartment, and behavior was videotaped for 15 min. Data are mean and SEM from 12 vehicle-treated, 9 low dose prepro-TRH178-199 $(0.6 \mu \mathrm{g} / \mathrm{kg})$-treated, and 6 high dose prepro-TRH178-199 $(6.0 \mu \mathrm{g} / \mathrm{kg})$-treated animals. * $p<0.05$ from vehicle.
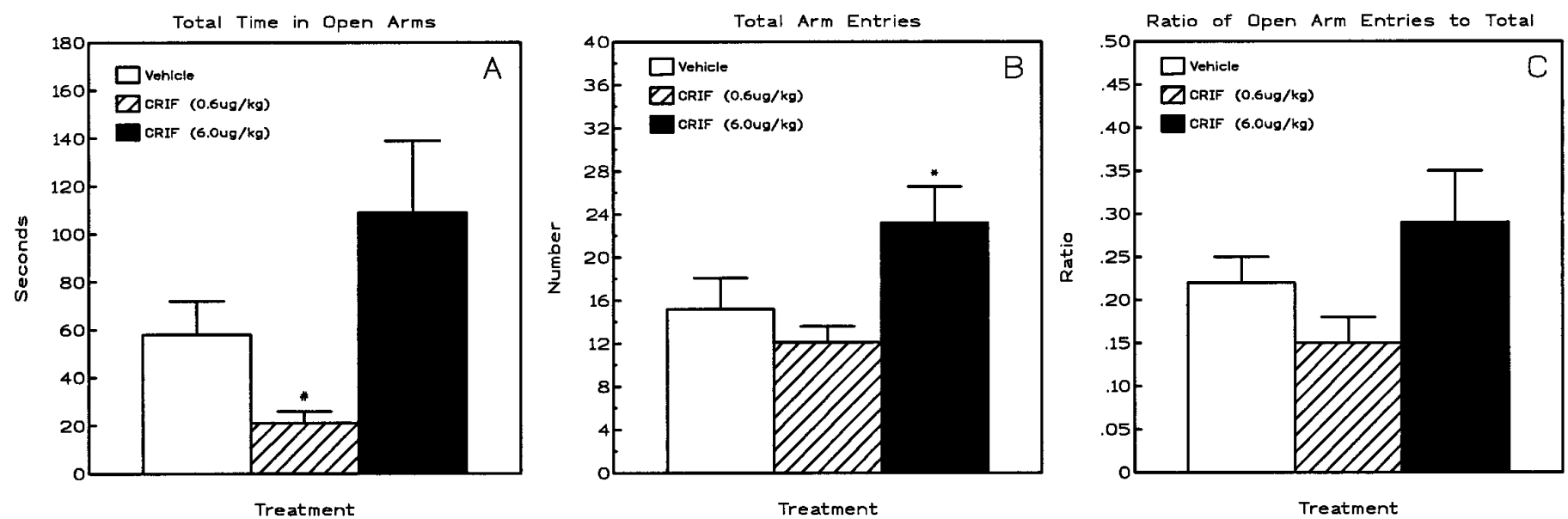

Figure 5. Behavioral responses in the plus maze after ICV infusion of prepro-TRH178-199 or the vehicle. Data are mean and SEM from eight vehicle-treated, seven low dose prepro-TRH178-199 $(0.6 \mu \mathrm{g} / \mathrm{kg})$-treated, and eight high dose prepro-TRH178-199 $(6.0 \mu \mathrm{g} / \mathrm{kg})$-treated animals. Average lighting in the testing room at the level of the maze was 200 lux. ${ }^{*} p<0.05$ from vehicle, using a sign test; ${ }^{*} p<0.05$ from prepro-TRH178-199 $(0.6 \mu \mathrm{g} / \mathrm{kg})$.

differential diffusion of the peptide from the ventricle to behaviorally active sites.

Although the behavioral data indicate that the peptide can decrease fear responsiveness, this reduction was not accompanied by an effect of the peptide on pituitary hormone release in response to restraint stress when it was injected ICV. This suggests that central actions of the peptide may not have the stimulus-reducing properties associated with classic anxiolytics, such as the benzodiazepines (Eisenberg, 1993; Owens et al., 1993). The peptide-induced increases in exploratory and locomotor behavior suggest a central effect on arousal or sensory systems. This is consistent with the increased grooming behavior in the open field induced by the peptide as well as the increase in active sniffing. Because the relationship of grooming behavior to stress shows an inverted U-shaped function, with a moderate degree of stress eliciting the greatest amount of the grooming behavior (van Erp et al., 1994), the absence of peptide-induced grooming in the elevated plus maze may reflect a more stressful situation for the animal than the open field.

The behavioral actions that we observed after ICV administration of prepro-TRH178-199, including increased exploration, increased grooming, and decreased fear of open areas, are consistent with anatomical identification of prepro-TRH178-199 immunoreactivity in brain areas known to be involved in mediating these behaviors as well as areas involved in sensory integration. These include the hypothalamus, periaqueductal gray, thal- 
amus, and septum (Lechan et al., 1987; Liao et al., 1988), all of which are easily accessible to ventricular dispersion after ICV administration of the peptide.

The immunocytochemical distribution of prepro-TRH178199 in brain suggests region-specific differential processing of prepro-TRH, because prepro-TRH178-199 immunostaining also is detected in regions that do not stain for TRH. Moreover, cryptic prepro-TRH sequences have been found to be post-translationally processed from the prohormone in the secretory granules (Lechan et al., 1987; Nillni et al., 1993, 1995). On the basis of the differential distribution between TRH and the non-TRH peptides, Lechan et al. (1987) suggested that these cryptic sequences might be biologically active neuromodulators. The present results support this proposition for prepro-TRH178-199.

In summary, prepro-TRH178-199 inhibits ACTH and PRL responses to stress at the level of the pituitary, whereas centrally it shows fear-reducing and arousing characteristics. These central and peripheral effects are unique and suggest the possibility that prepro-TRH peptides are part of a neuromodulatory system related to the processing of sensory information.

\section{REFERENCES}

Autelitano DJ, Lundblad JR, Blum M, Roberts JL (1989) Hormonal regulation of POMC gene expression. Annu Rev Physiol 51:715-726.

Ben-Jonathan N (1990) Prolactin releasing and inhibiting factors in the posterior pituitary. In: Neuroendocrine perspectives, Vol 8 (Muller EE, MacLeod RM, eds), pp 1-38. New York: Springer.

Blalock JE (1985) Pro-opiomelanocortin-derived peptides in the immune system. Clin Endocrinol 22:823-827.

Bulant M, Delfour A, Vaudry H, Nicholas P (1988) Processing of thyrotropin-releasing hormone prohormone (pro-TRH) generates proTRH connecting peptides. J Biol Chem 263:17189-17196.

de Goeij DC, Binnekade R, Tilders FJ (1993) Chronic stress enhances vasopressin, but not corticotropin-releasing factor secretion, during hypoglycemia. Am J Physiol 263:E394-E399.

de Wied D, Croiset C (1991) Stress modulation of learning and memory processes. Methods Achiev Exp Pathol 15:167-199.

de Wied D, de Kloet ER (1987) Pro-opiomelanocortin (POMC) as homeostatic control system. Ann NY Acad Sci 512:328-337.

Egdahl RH (1960) Adrenal cortical and medullary responses to trauma in dogs with isolated pituitaries. Endocrinology 66:200-216.

Eisenberg RM (1993) Sound vibration, a noninvasive stress: antagonism by diazepam. Psychopharmacology (Berl) 110:467-470.

Engeland WC, Miller P, Gann DS (1989) Dissociation between changes in plasma bioactive and immunoreactive adrenocorticotropin after hemorrhage in awake dogs. Endocrinology 124:2978-2985.

Engler D, Pham DT, Fullerton MJ, Funder JW, Clarke IJ (1988) Studies of the regulation of the hypothalamic-pituitary-adrenal axis in sheep with hypothalamic-pituitary disconnection. Neuroendocrinology 48 : 551-560.

Feldman S, Conforti N, Weidendeld J (1995) Limbic pathways and hypothalamic neurotransmitters mediating the adrenocortical responses to neural stimuli. Neurosci Biobehav Rev 19:235-240.

Fitch RH, McGivern RF, Redei E, Schrott L, Cowell PE, Denenberg VH (1992) Neonatal ovariectomy and pituitary-adrenal responsiveness in the adult rat. Acta Endocrinol 126:44-48.

Gold PE, van Buskirk R (1976) Effects of post-trial hormone injections on memory processes. Horm Behav 1:509-517.

Halasz B, Vernikos-Danellis J, Gorski RA (1967) Pituitary ACTH content in rats after partial or total interruption of neural afferents to the medial basal hypothalamus. Endocrinology 81:921-924.

Handley SL, McBlane JW (1993) An assessment of the elevated X-maze for studying anxiety-modulating drugs. J Pharmacol Toxicol Methods 29:129-138.

Harris GW (1948) Neural control of the pituitary gland. Physiol Rev 28:134-179.

Harvey S, Cogburn LA (1996) Cryptic peptides of prepro-TRH antagonize TRH-induced GH secretion in chickens at extrapituitary sites. J Endocrinol 151:359-364.
Higuchi T, Negoro H, Arita J (1989) Reduced responses of prolactin and catecholamine to stress in the lactating rat. J Endocrinol 122:495-498.

Kalin NH, Takahashi LK, Chen FL (1994) Restraint stress increases corticotropin-releasing hormone mRNA content in the amygdala and paraventricular nucleus. Brain Res 656:182-186.

Kjaer A, Knigge U, Warberg J (1994) Histamine- and stress-induced prolactin secretion: importance of $\mathrm{V}_{1^{-}}$and $\mathrm{V}_{2}$-receptors. Eur $\mathrm{J}$ Endocrinol 131:391-397.

Korte SM, Bouws GAH, Bohus B (1993) Central actions of corticotropin-releasing hormone $(\mathrm{CRH})$ on behavioral, neuroendocrine, and cardiovascular regulation: brain corticoid receptor involvement. Horm Behav 27:167-183.

Landgraf R, Gerstberger R, Montkowski A, Probst JC, Wotjak CT, Holsboer F, Engelmann M (1995) $V_{1}$ vasopressin receptor antisense oligodeoxynucleotide into septum reduced vasopressin binding, social discrimination abilities, and anxiety-related behavior in rats. J Neurosci 15:4250-4258.

Lechan RM, Wu P, Jackson IMD (1987) Immunocytochemical distribution in rat brain of putative peptides derived from thyrotropin-releasing hormone prohormone. Endocrinology 121:1879-1891.

Li Q, Levt AD, Cabrera TM, Brownfield MS, Battaglia G, Van de Kar LD (1993) Long-term fluoxetine, but not desipramine, inhibits the ACTH and oxytocin responses to 5-HT1A agonist 8-OH-DPAT in male rats. Brain Res 630:148-156.

Liao N, Bulant M, Nicholas P, Vaudry H, Pelletier G (1988) Immunocytochemical distribution of neurons containing a peptide derived from thyrotropin-releasing hormone precursor in the rat brain. Neurosci Lett 85:24-28.

Lichtensteiger W, Monnet F (1979) Differential response of dopamine neurons to $\alpha$-melanotropin and analogs in relation to their endocrine actions. Life Sci 25:2079-2087.

Liu JW, Ben-Jonathan N (1994) Prolactin-releasing activity of neurohypophysial hormones: structure-function relationship. Endocrinology 134:114-118.

Lundblad JR, Roberts JL (1988) Regulation of pro-opiomelanocortin gene expression in pituitary. Endocr Rev 9:135-158.

Mercer JE, Clements JA, Clarke IJ, Funder JW (1989) Glucocorticoid regulation of pro-opiomelanocortin gene expression in the pituitary gland of hypothalamopituitary intact and hypothalamopituitary disconnected sheep. Neuroendocrinology 50:280-285.

Nicholson WE, Orth DN (1996) Prepro-thyrotropin-releasing hormone (178-199) does not inhibit corticotropin release. Endocrinology 137:2171-2174.

Nillni EA, Sevarino KA, Jackson IM (1993) Identification of the thyrotropin-releasing hormone-prohormone and its post-translational processing in a transfected AtT20 tumoral cell line. Endocrinology 132:1260-1270.

Nillni EA, Friedman TC, Todd RB, Birch NP, Loh YP, Jackson IM (1995) Pro-thyrotropin-releasing hormone processing by recombinant PC1. J Neurochem 65:2462-2472.

Owens MJ, Vargas MA, Nemeroff CB (1993) The effects of alprazolam on corticotropin-releasing factor neurons in the rat brain: implications for a role for CRF in the pathogenesis of anxiety disorders. J Psychiatr Res 27[Suppl 1]:209-220.

Paxinos G, Watson C (1986) The rat brain in stereotaxic coordinates. Sydney: Academic.

Redei E, Hilderbrand H, Aird F (1995a) Corticotropin release-inhibiting factor is encoded within prepro-TRH. Endocrinology 136:1813-1816.

Redei E, Hilderbrand H, Aird F (1995b) Corticotropin release-inhibiting factor is prepro-thyrotropin-releasing hormone (178-199). Endocrinology 136:3557-3563.

Reichlin S (1992) Neuroendocrinology. In: Williams textbook of endocrinology (Wilson JD, Foster DW, eds), pp 135-219. Philadelphia: Saunders.

Romero LM, Plotsky PM, Sapolsky RM (1993) Patterns of adrenocorticotropin secretagogue release with hypoglycemia, novelty, and restraint after colchicine blockade of axonal transport. Endocrinology 132: 199-204.

Rots NY, Cools AR, Oitzl MS, deJong J, Sutanto W, de Kloet RE (1996) Divergent prolactin and pituitary-adrenal activity in rats selectively bred for different dopamine responsiveness. Endocrinology 137:1678-1686.

Roussel JP, Teresi S, Vaudry H, Astier H (1994) A cryptic peptide of 
TRH prohormone inhibits TRH-induced GH release. C R Acad Sci Ser III Sci Vie 317:270-276.

Sands SF, Wright AA (1979) Enhancement and disruption of retention performance by ACTH in a choice task. Behav Neural Biol 27:413-422.

Schotman P, Allaart J (1981) Biphasic modulation by ACTH-like peptides on protein synthesis in a cell-free system from rat brain. J Neurochem 37:1349-1352.

Selye H (1950) The physiology and pathology of exposure to stress. Montreal: Acta.

Vale W, Spiess J, Rivier C, Rivier J (1981) Characterization of a 41residue ovine hypothalamic peptide that stimulates secretion of corticotropin and $\beta$-endorphin. Science 213:1394-1397.

Valentijn K, Bunel DT, Liao N, Pelletier G, Vaudry H (1991) Release of pro-thyrotropin-releasing hormone connecting peptides PS4 and PS5 from perfused rat hypothalamic slices. Neuroscience 44:223-233.

van Erp AMM, Kruk MR, Meelis W, Willekens-Bramer DC (1994) Effect of environmental stressors on time course, variability, and form of self-grooming in the rat: handling, social contact, defeat, novelty, restraint, and fur moistening. Behav Brain Res 65:47-55.

van Oers JWAM, Hinson JP, Binnekade R, Tilders FJH (1992) Physiological role of corticotropin-releasing factor in the control of adrenocorticotropin-mediated corticosterone release from the rat adrenal gland. Endocrinology 130:282-288.

Walker C-D, Trottier G, Rochford J, Lavallee D (1995) Dissociation between behavioral and hormonal responses to the forced swim stress in lactating rats. J Neuroendocrinol 7:615-622. 